\title{
Ancient heat flow, crustal thickness, and lithospheric mantle rheology in the Amenthes region, Mars
}

\author{
Javier Ruiz ${ }^{\mathrm{a}, *}$, Carlos Fernández ${ }^{\mathrm{b}}$, David Gomez-Ortiz ${ }^{\mathrm{c}}$, \\ James M. Dohm ${ }^{\mathrm{d}, \mathrm{e}}$, Valle López ${ }^{\mathrm{f}}$, Rosa Tejero ${ }^{\mathrm{g}}$ \\ ${ }^{a}$ Museo Nacional de Ciencias Naturales, CSIC, José Gutiérrez Abascal 2, 28006 Madrid, Spain \\ ${ }^{\mathrm{b}}$ Departamento de Geodinámica y Paleontología, Universidad de Huelva, Campus de El Carmen, 21071 Huelva, Spain \\ ${ }^{c}$ ESCET - Área de Geología, Universidad Rey Juan Carlos, 28933 Móstoles, Spain \\ ${ }^{\mathrm{d}}$ Department of Hydrology and Water Resources, University of Arizona, Tucson 85721, AZ, USA \\ ${ }^{\mathrm{e}}$ Lunar and Planetary Laboratory, University of Arizona. Tucson 85721, AZ, USA \\ ${ }^{\mathrm{f}}$ Instituto Español de Oceanografia, Servicios Centrales, Corazón de María 8, 28002 Madrid, Spain \\ ${ }^{g}$ Departamento de Geodinámica, Facultad de Ciencias Geológicas, Universidad Complutense de Madrid, 28040 Madrid, Spain
}

Received 1 October 2007; received in revised form 4 February 2008; accepted 5 February 2008

Available online 23 February 2008

Editor: T. Spohn

\begin{abstract}
Surface heat flow calculations for the Amenthes region of Mars can be independently performed using the depth to the brittle-ductile transition and the effective elastic thickness of the lithosphere estimated for the Late Noachian/Early Hesperian (equivalent to an estimated absolute age of $\sim 3.6-3.8 \mathrm{Ga}$ ). This, along with crustal heat production rates estimated from heat-producing elements abundances, permits us to put constraints, for that particular place and time, on both the thermal and mechanical properties of the lithosphere and the crustal thickness. The depth to the brittleductile transition deduced from modeling of the topography of Amenthes Rupes is $27-35 \mathrm{~km}$, and the associated surface heat flow is $26-37 \mathrm{~mW} \mathrm{~m}^{-2}$. On the other hand, the effective elastic thickness in this region is between 19 and $35 \mathrm{~km}$ : the surface heat flow deduced by considering crustal and lithospheric mantle contributions to the total lithospheric strength, as well as wet or dry olivine for lithospheric mantle rheology, is $31-49 \mathrm{~mW} \mathrm{~m}^{-2}$. The relatively limited overlap among $T_{\mathrm{e}}$ - and $z_{\mathrm{BDT}}$-based heat flow values implies a surface heat flow of $31-36 \mathrm{~mW} \mathrm{~m}^{-2}$ (with a high fraction originated from crustal heat sources) and a wet mantle rheology. The so obtained local crustal thickness is $43-74 \mathrm{~km}$, which suggests an average thickness of $\sim 40-75 \mathrm{~km}$ for the Martian crust; for the frequently used crustal density of $2900 \mathrm{~kg} \mathrm{~m}^{-3}$, our results suggest a crustal thickness of 50-63 km for the Amenthes region, and an average crustal thickness of $\sim 45-65 \mathrm{~km}$ for Mars.
\end{abstract}

\section{Introduction}

Estimations of crustal thickness for Mars have been proposed from several methods: inversions of gravity and topography (e.g., Zuber et al., 2000; Nimmo, 2002; Turcotte et al., 2002; Neumann et al., 2004) or geoid and topography (Wieczorek and Zuber,

\footnotetext{
* Corresponding author. Fax: +34 915644740.

E-mail addresses: ruiz@mncn.csic.es, jaruiz@geo.ucm.es (J. Ruiz).
}

2004) relations, moment of inertia constraints (e.g., Sohl and Spohn, 1997; Bertka and Fei, 1998a,b), compositional and isotopic mass-balance (Normam, 1999, 2002; McLennan, 2001; Wieczorek and Zuber, 2004; Taylor et al., 2006), or requirements for the maintenance of crustal thickness variations against relaxation due to flow of the lower crust (Zuber et al., 2000; Nimmo and Stevenson, 2001). These estimations assume constant crustal density as a necessary simplification. By simultaneously considering several geophysical and geochemical considerations, the average thickness of the Martian crust has been constrained to be between 38 and $62 \mathrm{~km}$ (Wieczorek and Zuber, 2004). 
Calculations of surface heat flow on Mars (or, equivalently, thermal gradients) have been performed from the effective elastic thickness of the lithosphere (Solomon and Head, 1990; Anderson and Grimm, 1998; Zuber et al., 2000; McGovern et al., 2002, 2004; Kiefer, 2004; Grott et al., 2005; Kronberg et al., 2007) or from the depth to the brittle-ductile transition beneath large faults (Schultz and Watters, 2001; Schultz and Lin, 2001; Grott et al., 2007). Ruiz et al. (2006a,b) have pointed out the importance of taking into account crustal heat sources in the calculation of surface heat flows from effective elastic thicknesses or brittleductile transition depths. In this sense, the recently presented abundances of potassium and thorium (from which uranium abundances can be estimated from cosmochemical considerations) based on Mars Odyssey Gamma Ray Spectrometer (GRS) data (e.g., Taylor et al., 2006) permit us to refine the calculations of the thermal structure of the Martian crust.

If there are estimations of effective elastic thickness $\left(T_{\mathrm{e}}\right)$ and depth to the brittle-ductile transition $\left(Z_{\mathrm{BDT}}\right)$ for a particular region and time, then heat flow calculations based on both temperature-in-depth indicators should be (at least roughly) consistent. This potentially permits constraining for the thermal structure and the distribution of heat sources in the lithosphere (Ruiz et al., 2006b). The Amenthes region (Fig. 1) is therefore adequate for analyzing the thermal structure and thickness of the Martian crust, since estimations of both the brittle-ductile transition depth (Schultz and Watters, 2001; Grott et al., 2007; this work, Section 3) and the effective elastic thickness of the lithosphere (Watters, 2003a; Watters and McGovern, 2006;
Milbury et al., 2007; this work, Section 4) are possible for the Late Noachian/Early Hesperian time. As such, we analyze the Late Noachian/Early Hesperian surface heat flow of the Amenthes region by considering homogeneously distributed crustal heat sources, which have abundances based on the latest GRS data reported by Taylor et al. (2006), and crustal and lithospheric mantle contributions to the total strength, and hence to the effective elastic thickness, of the lithosphere (see Ruiz et al., 2006b). This permits us to constrain the thickness of the Martian crust in a way independent from previous works. We also consider dry and wet rheologies for the lithosperic mantle. In the following, the theoretical methodologies are described, as well as their application to the Amenthes region.

\section{Temperature profiles}

Temperature profiles are calculated by assuming radioactive heat sources homogeneously distributed in the upper crust. This is based on GRS results, which suggest a Martian crust much less geochemically varied than the Earth's crust (Taylor et al., 2006). Previously, Ruiz et al. (2006b) suggested the existence of a heat-producing element (HPE)-rich upper layer, thinner than the whole crust, for Solis Planum region, on the basis of $T_{\mathrm{e}}$ - and $Z_{\mathrm{BDT}}$-based heat flow calculations, but these calculations used HPE abundances based on preliminary GRS data (Taylor et al., 2003a,b). However, the updated GRS data (Taylor et al., 2006) show lower HPE abundances than those data preliminary reported, and it must be noted that the capability to distinguish a

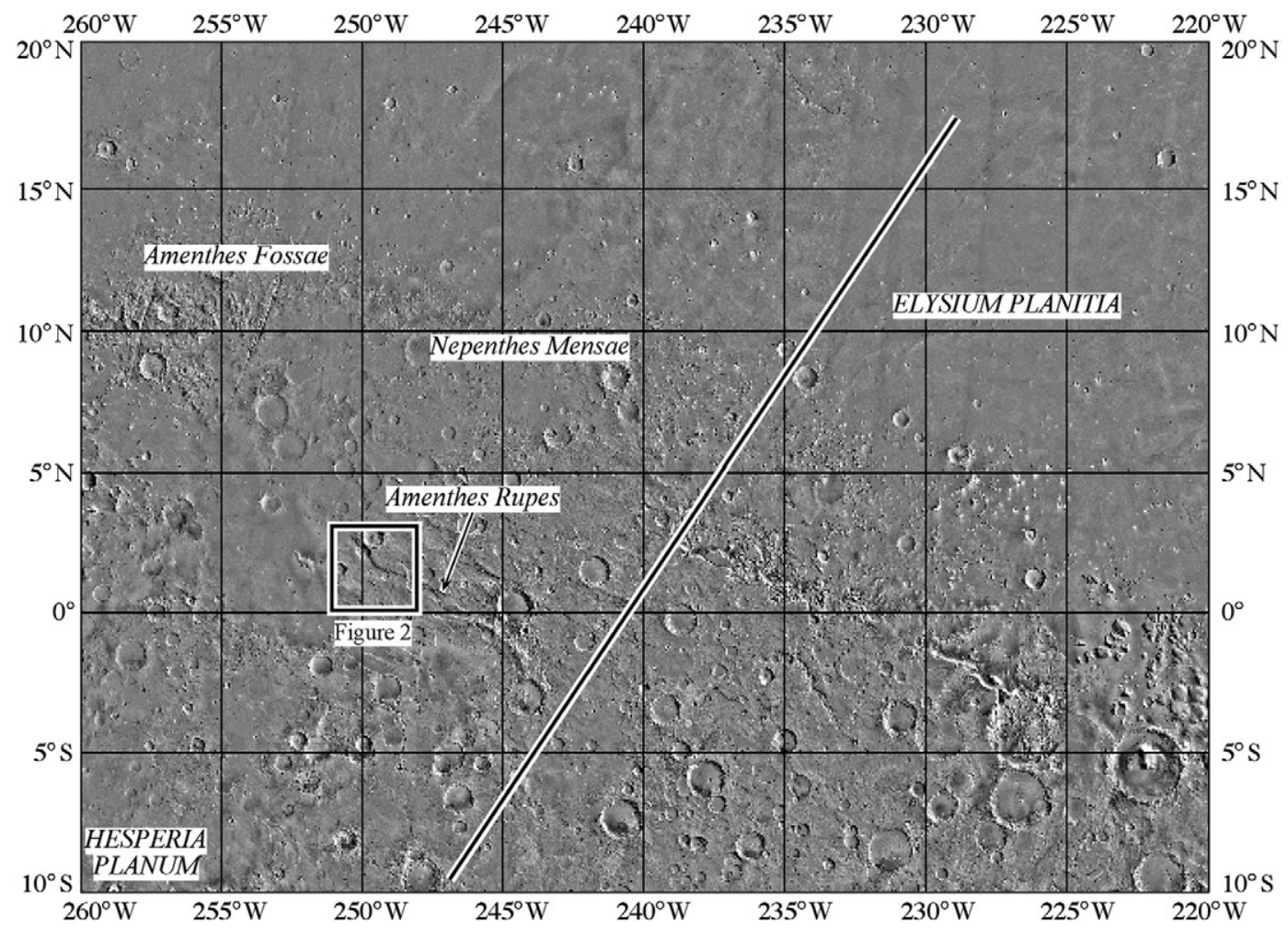

Fig. 1. Digital Elevation Model (MOLA $1 / 32^{\circ}$ gridded topography) of the Amenthes region, showing the trace of the profile used to determine the effective elastic thickness (see Section 4) and the location of the area enlarged in Fig. 2. 
differentiated crustal structure decreases for low HPE abundances (Ruiz et al., 2006b). So, within the crust, the temperature at depth $z$ is

$T_{z}=T_{\mathrm{s}}+\frac{F z}{k_{\mathrm{c}}}-\frac{H z^{2}}{2 k_{\mathrm{c}}}$,

where $T_{\mathrm{s}}$ is the surface temperature, $F$ is the surface heat flow, $k_{\mathrm{c}}$ is the thermal conductivity of the crust, and $H$ is the volumetric heat production rate. A linear thermal gradient is assumed for the lithospheric mantle (radiogenic sources are expected to be sparse in the lithospheric mantle, and the heat flow can be assumed constant; e.g., Turcotte and Schubert, 2002), according to

$T_{z}=T_{\mathrm{b}}+\frac{(F-H b)(b-z)}{k_{\mathrm{m}}}$,

where $T_{\mathrm{b}}$ is the temperature at the base of the radioactive element-rich layer [obtained by using $z=z_{\mathrm{b}}$ in Eq. (1)], $b$ is the thickness of the crust, and $k_{\mathrm{m}}$ is the thermal conductivity of the lithospheric mantle.

We use a surface temperature of $220 \mathrm{~K}$, the present-day mean surface temperature (Kieffer et al., 1977), in our calculations. Previous works used different values of the thermal conductivity of the crust, for example: $2 \mathrm{~W} \mathrm{~m}^{-1} \mathrm{~K}^{-1}$ (Clifford, 1993; Grott et al., 2005, 2007; Kronberg et al., 2007), $2.5 \mathrm{~W} \mathrm{~m}^{-1} \mathrm{~K}^{-1}$ (Solomon and Head, 1990; McGovern et al., 2002, 2004; Ruiz et al., 2006a,b), or 3.2-3.3 $\mathrm{W} \mathrm{m}^{-1} \mathrm{~K}^{-1}$ (Anderson and Grimm, 1998; Schultz and Watters, 2001). Taking into account the effects of possible composition, porosity, filling materials, and temperature-dependent thermal conductivity, a columnaveraged thermal conductivity of $2 \pm 1 \mathrm{~W} \mathrm{~m}^{-1} \mathrm{~K}^{-1}$ can be assumed for the upper Martian crust (Clifford, 1993). Moreover, at temperatures of several hundreds of degrees centigrade a wide variety of crustal rocks have thermal conductivities close to $2 \mathrm{~W} \mathrm{~m}^{-1} \mathrm{~K}^{-1}$ (e.g., Bonner et al., 2003). Thus, a thermal conductivity of $2 \mathrm{~W} \mathrm{~m}^{-1} \mathrm{~K}^{-1}$ is used here for the entire crust. On the other hand, the thermal conductivity of the lithospheric mantle is assumed to be $3.5 \mathrm{~W} \mathrm{~m}^{-1} \mathrm{~K}^{-1}$, a value typically used for the terrestrial lithospheric mantle (e.g., Burov and Diament, 1995).

The volumetric heating rate in the crust depends on both the amount of HPE and time before present. Measurements of potassium and thorium abundances, as well as $\mathrm{K} / \mathrm{Th}$ ratios, show a wide variation on the surface (Taylor et al., 2006). In this paper, we use crustal potassium and thorium abundances of $3630 \pm 20$ and $0.70 \pm 0.02 \mathrm{ppm}$ respectively, average values deduced from GRS data for the ancient southern highlands (Taylor et al., 2006). For uranium abundance, we use a $\mathrm{Th} / \mathrm{U}$ ratio of 3.6 deduced from SNC meteorite geochemistry (McLennan, 2003). Absolute age for the beginning of the Late Noachian and the end of the Early Hesperian are $3.8 \mathrm{Ga}$ and $3.6 \mathrm{Ga}$, respectively, following the cratering chronology of Hartmann and Neukum (2001). We calculate crustal volumetric heat production rates by using crustal densities between $2700 \mathrm{~kg} \mathrm{~m}^{-3}$ and $3100 \mathrm{~kg} \mathrm{~m}^{-3}$ (Wieczorek and Zuber, 2004), and decay constants from Turcotte and Schubert (2002), obtaining volumetric heat production

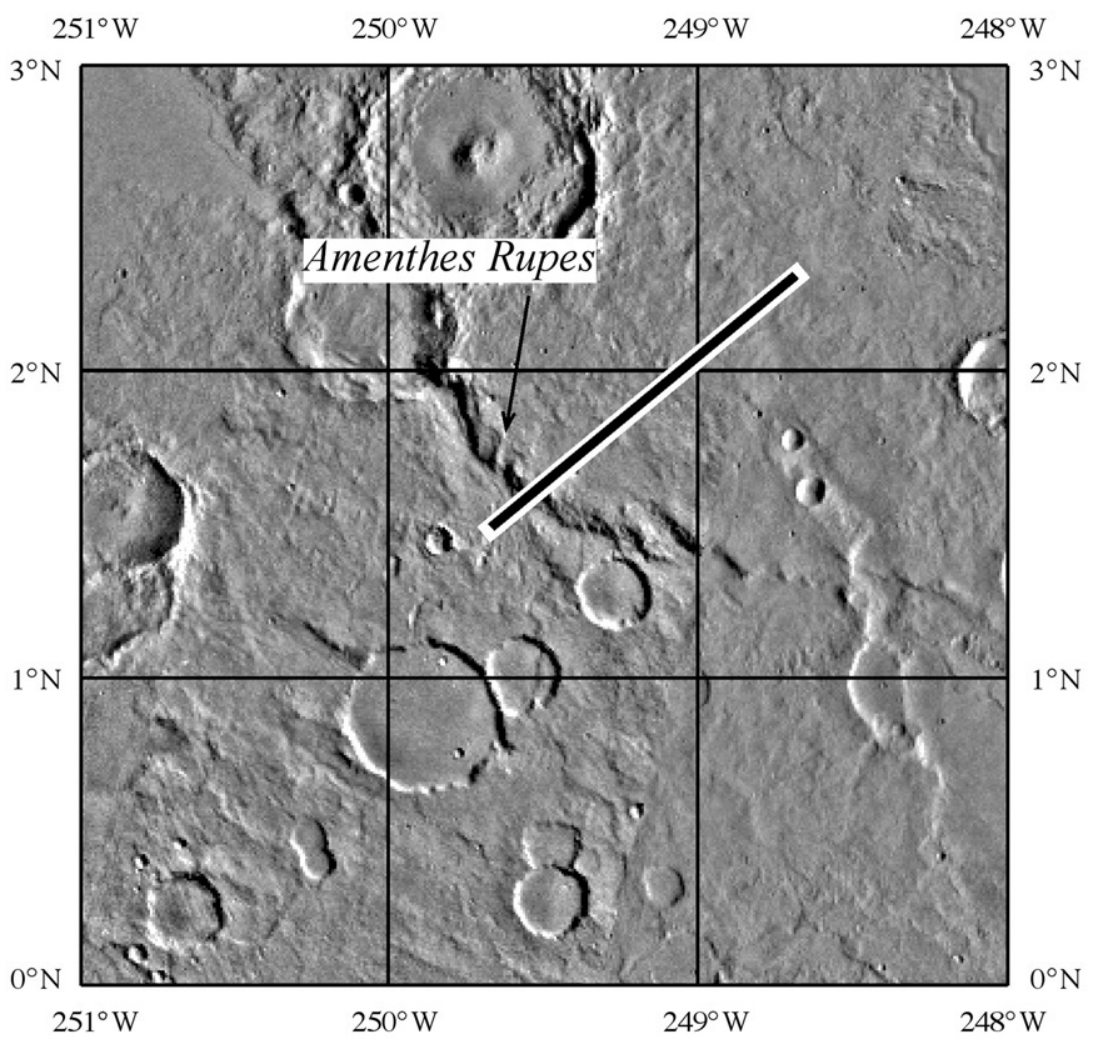

Fig. 2. Digital Elevation Model (MOLA 1/128 ${ }^{\circ}$ gridded topography) of the Amenthes Rupes showing the trace of the profile used to determine the depth of Amenthesrelated thrust fault. 
rates between 0.46 and $0.60 \mu \mathrm{W} \mathrm{m} \mathrm{m}^{-3}$ (or, equivalently, heat production rates by mass unity between 1.70 and $1.95 \times$ $\left.10^{-4} \mu \mathrm{W} \mathrm{kg}^{-1}\right)$.

\section{The depth of Amenthes Rupes-related thrust fault}

Amenthes Rupes is the largest lobate scarp on Mars, reported to have formed during the Late Noachian/Early Hesperian (e.g., Watters and Robinson, 1999; Watters, 2003b). Martian lobate scarps are usually interpreted to be large thrust faults (e.g., Watters and Robinson, 1999), which must deform the crust down to the brittle-ductile transition depth (Schultz and Watters, 2001; Grott et al., 2007). Using the forward modeling procedure, Schultz and Watters (2001) obtained a best fit to the topography of Amenthes Rupes for a depth of faulting of 25-30 km. Through a similar procedure, Grott et al. (2007) found a depth of faulting of 32-40 km for this same feature. Since the two results do not overlap, we have also estimated the depth of Amenthes Rupes-related thrust faulting through the forward modeling procedure along a MOLA-based profile from $249.6^{\circ} \mathrm{W}\left(110.40^{\circ} \mathrm{E}\right), 1.52^{\circ} \mathrm{N}$ to $248.62^{\circ} \mathrm{W}\left(111.38^{\circ} \mathrm{E}\right), 2.34^{\circ} \mathrm{N}$ (Fig. 2).

We used the mechanical dislocation program, Coulomb 2.5 (Lin and Stein, 2004; Toda et al., 2005; available online at http:// quake.usgs.gov/research/deformation/modeling/coulomb/), which allows us to predict the surface displacement associated with faulting for a range of significant parameters such as the elastic constants, fault dip and depth, and magnitude and sense of offset along the fault. Application of this model to Mars is described in more detail in Schultz and Lin (2001) and Schultz and Watters (2001). Comparison of the MOLA $1 / 128^{\circ}$ digital elevation model with the structural topography predicted above a given fault by Coulomb permits the identification of a narrow range of admissible fault dips, depths, and displacements.

For the values of the elastic parameters, a Young's modulus of $100 \mathrm{GPa}$ and a Poisson's coefficient of 0.25 are assumed. Reasonable variations in these parameters do not produce significant variations in the obtained depth of faulting (e.g., Schultz and Watters, 2001). The MOLA profile perpendicular to the trace of Amenthes Rupes shows a marked topographic offset, with the trailing synclinal depression standing more than $300 \mathrm{~m}$ above the leading syncline (Fig. 3a), which corresponds to the approximate location of the fault surface trace. The Amenthes region generally exhibits a SSW slope. Though the origin of this slope is beyond the scope of this work, the use of the forward mechanical modeling program requires the regional slope to be filtered to obtain a detrended topography. Inspection of the topography in the Amenthes region suggests that a simple linear detrending can be sufficiently accurate in this case (Fig. $3 b$ and c).

Comparing the position of the trailing syncline between the MOLA topography and the modeled relief (Grott et al., 2007) is not useful as a fitting constraint here, because the trailing syncline of the Amenthes Rupes is masked by another nearby (unnamed) scarp located $20 \mathrm{~km}$ to the NE (arrow in Fig. 3a). Therefore, it has been modeled only the relief associated with the main anticline (dashed rectangle in Fig. 3a). The best fit for the topography of Amenthes Rupes was determined by calculating
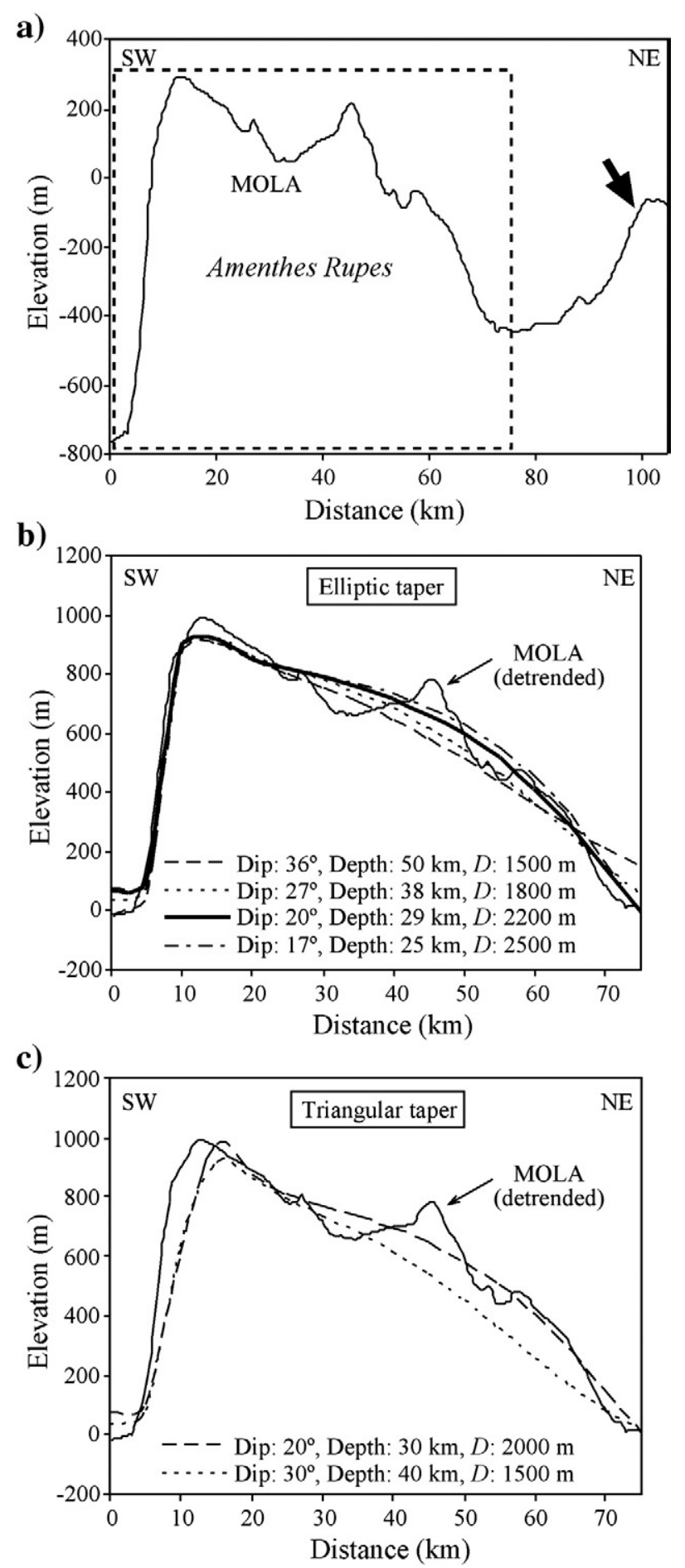

Fig. 3. Estimation of the depth of the Amenthes-related thrust fault. (a) MOLA profile used (see Fig. 2). The arrow points to a small scarp located near the NE end of the Amenthes Rupes. The dashed rectangle indicates the segment used in the mechanical modeling (see text for explanation). Vertical exaggeration $=64.2: 1$. (b) Comparison between the surface topography above a thrust fault with an elliptic shaped slip profile and the detrended MOLA topography. Relief profiles for four mechanical models have been represented. Choice of these models follows from the best fit procedure explained in the main text. (c) Similar to (b) for a fault with a triangularshaped slip profile. See text for explanation. Vertical exaggeration in (b) and (c) $=42.4: 1$. 
the $l^{2}$-norm of the difference between the detrended MOLA topography and the predictions of the mechanical dislocation program (Kronberg et al., 2007). Values of root of mean square (RMS) for a range of dip angles $\left(16^{\circ}-37^{\circ}\right.$, step size of $\left.1^{\circ}\right)$ and depth of faulting (20-52 km, step size of $1 \mathrm{~km}$ ), and for three fault offsets $(D=1500,2000$ and $2500 \mathrm{~m})$ are shown in Fig. 4. The calculated topography depends on the slip distribution on the fault surface (e.g., Schultz and Watters, 2001; Grott et al., 2007). Here, an elliptic tapered slip distribution with a linear taper to within $10 \mathrm{~km}$ of fault tips has been adopted to avoid stress singularities (Schultz and Watters, 2001). This choice will be discussed later.

Fig. 4a shows that fault offsets of $1500 \mathrm{~m}$ yield poor fits (RMS errors larger than $80 \mathrm{~m}$ ), with the lower values associated with large fault depths $(50 \mathrm{~km})$ and fault dip angles $\left(36^{\circ}\right)$. Instead, for fault offsets of $2000 \mathrm{~m}$, the modeled relief better matches the observed topography (minimum RMS value of $58.4 \mathrm{~m}$ ), although with lower dip angle $\left(23^{\circ}\right)$ and fault depth $(33 \mathrm{~km})$. Poorer fits are obtained for fault offsets of $2500 \mathrm{~m}$ (Fig. 4c). Interestingly, the best fitting values for each fault offset seem located along a straight line on the fault depth against fault dip diagrams (Fig. 4a to c). To illustrate this dependence, Fig. 4d shows the computed minimum RMS errors for fault offsets ranging from 1500 to 2500 (step size of $100 \mathrm{~m}$ ). The predicted relief for some of these models can be observed in Fig. 3b. Inset in Fig. 4d shows that the modeled relief that best matches the observed topography is obtained for a fault offset of 2200 , fault dip of $20^{\circ}$ and fault depth of $29 \mathrm{~km}$ (black triangle, RMS error value of $58.1 \mathrm{~m}$ ). The bold line in Fig. $3 \mathrm{~b}$ corresponds to this specific case. However, a range of fault parameters with similar RMS error values should be considered. The curve of best fitting RMS errors as a function of fault depth (inset in Fig. 4d) is relatively flat for values lower than $60 \mathrm{~m}$, whereas it has steep branches for values larger than $60 \mathrm{~m}$. This value is therefore a reasonable threshold for the range of admissible RMS errors. Thus, it can be concluded that fault offsets of 1900-2300 m, fault dips of $19^{\circ}-24^{\circ}$ and fault depths of $27-35 \mathrm{~km}$ yield the best fitting parameters (Fig. 4d).

Grott et al. (2007) have suggested that a triangular-shaped slip profile along the fault could be also considered to calculate surface displacements. RMS values for a triangular taper have been computed here for the same range of parameters than in the elliptic taper case. Results show consistently larger RMS error for the triangular taper. In fact, the minimum estimated RMS error is a)

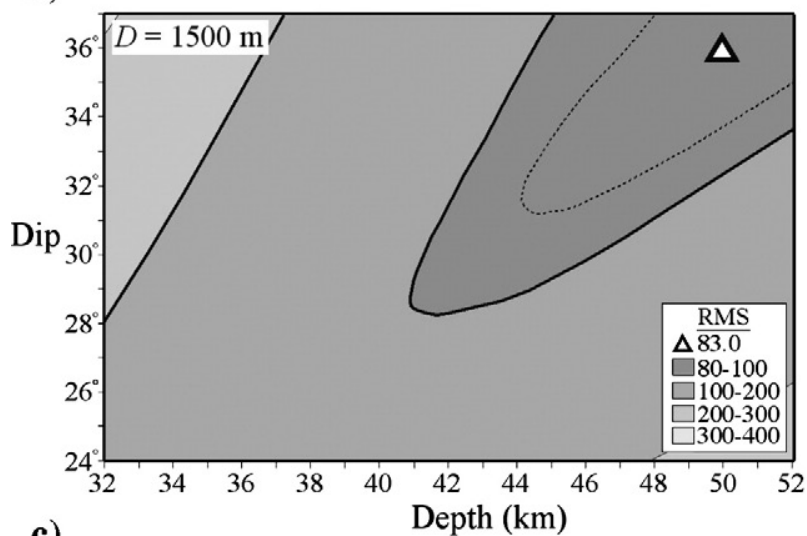

c)

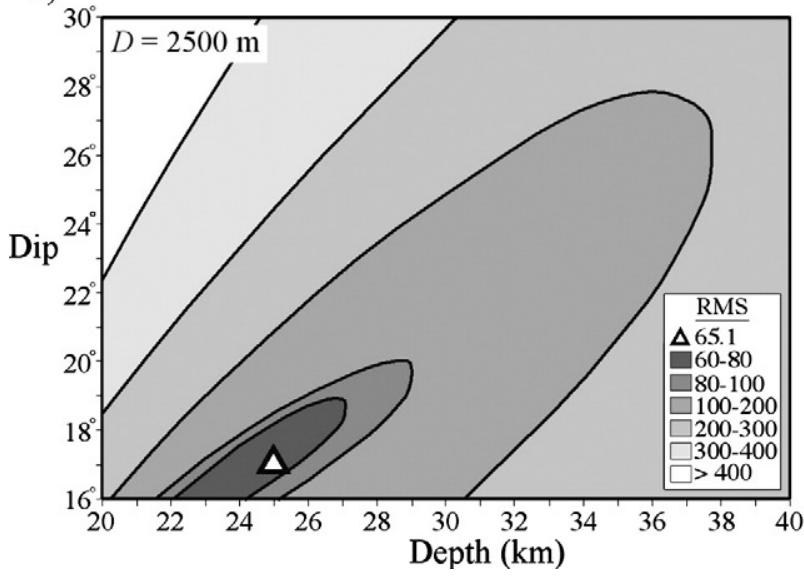

b)

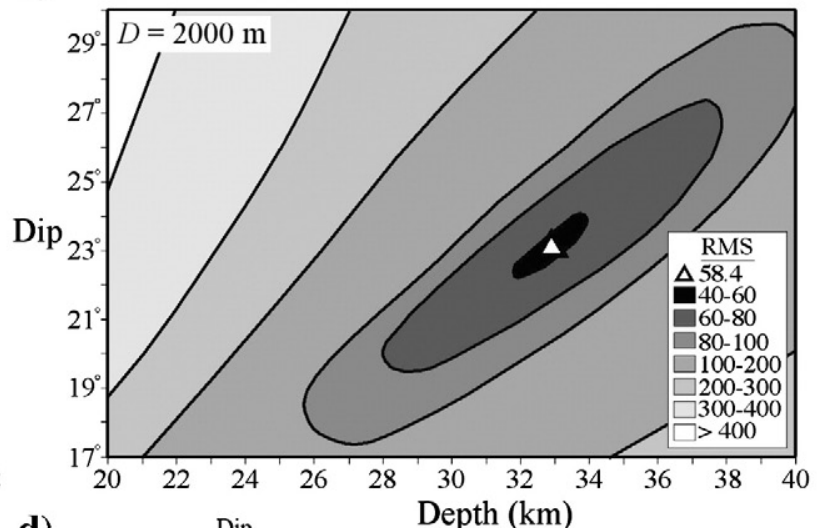

d)

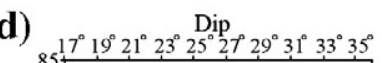

Depth $(\mathrm{km})$

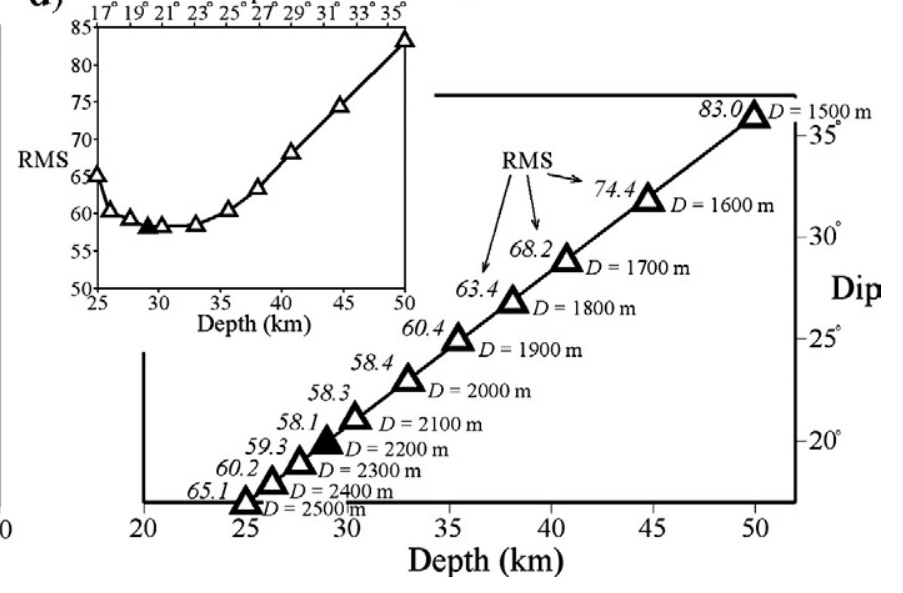

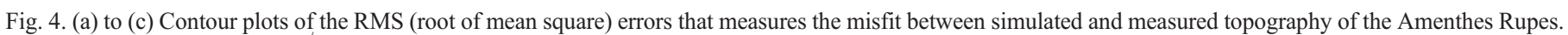

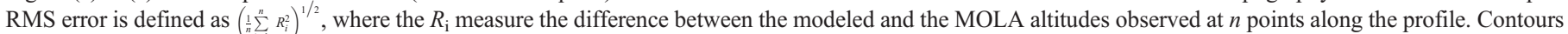

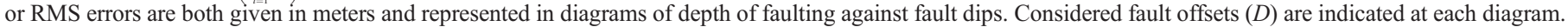

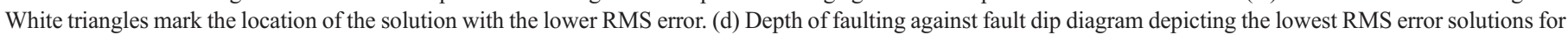

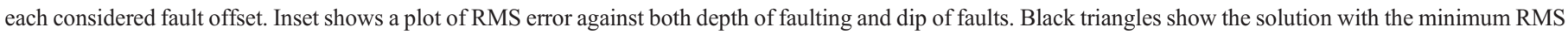
error value. 
of $90.7 \mathrm{~m}$, for an offset of $2000 \mathrm{~m}$. Although a triangular-shaped slip profile accurately reflects the shape of the crest of the Rupes, it underestimates the slope at its frontal scarp (Fig. 3c). Linear offset distributions yield very large RMS errors, and their corresponding models are not presented in this work. Therefore, the results of the elliptical slip distributions are preferred here.

\section{Heat flow from the depth of Amenthes Rupes-related thrust fault}

The range for the depth of Amenthes Rupes-related faulting obtained in the previous section $(27-35 \mathrm{~km})$ overlaps with, and is somewhat intermediate between, those proposed by Schultz and Watters (2001) and Grott et al. (2007). This depth lies within the crust (see Wieczorek and Zuber, 2004; Neumann et al., 2004). Moreover, the large depth of faulting suggests that it represents the crustal brittle-ductile transition (Schultz and Watters, 2001; Grott et al., 2007). The temperature at the brittleductile transition depth can be obtained from the temperature dependence of ductile strength. In turn, the knowledge of the temperature at the brittle-ductile transition depth allows the calculation of the surface heat flow by matching to a temperature profile (e.g., Ruiz and Tejero, 2000; Ruiz et al., 2006b).

The brittle strength is calculated for zero pore pressure, according to the expression

$\left(\sigma_{1}-\sigma_{3}\right)_{b}=\alpha \rho g z$,

where $\alpha$ is a coefficient depending on the stress regime (which is $s$ for pure compression, appropriate for thrust faulting, and 0.75 for pure tension; e.g., Sibson, 1974; Ranalli, 1997), $\rho$ is the density, $g$ is the acceleration due to the gravity $\left(3.72 \mathrm{~m} \mathrm{~s}^{-2}\right.$ for Mars), and $z$ is the depth. The ductile strength is given by

$\left(\sigma_{1}-\sigma_{3}\right)_{d}=\left(\frac{\dot{e}}{A}\right)^{1 / n} \exp \left(\frac{Q}{n R T}\right)$

where $\dot{e}$ is the strain rate, $A$ and $n$ are laboratory-determined constants, $Q$ is the activation energy of creep, $R(=8.31447 \mathrm{~J}$ $\mathrm{mol}^{-1} \mathrm{~K}^{-1}$ ) is the gas constant, and $T$ is the absolute temperature. Strain rates of $10^{-16} \mathrm{~s}^{-1}$ and $10^{-19} \mathrm{~s}^{-1}$ are used in the calculations, based on the range previously considered for Mars (McGovern et al., 2002, 2004). Terrestrial intraplate strain rates are typically $\sim 10^{-16} \mathrm{~s}^{-1}$ (e.g., Tesauro et al., 2007); on the other hand, Schultz (2003), by assuming fault slip rates similar to the terrestrial ones, obtained $\dot{e}=10^{-19}-10^{-17} \mathrm{~s}^{-1}$ for the Amenthes thrust fault population. For creep parameters of the Martian crust we use the constants for the flow law of diabase: $A=0.0612 \mathrm{MPa}^{-n} \mathrm{~s}^{-1}, n=3.05$ and $Q=276 \mathrm{~kJ} \mathrm{~mol}^{-1}$ (Caristan, 1982). The use of a "standard" wet diabase for the Martian crust is consistent with extensive evidence for water-related geological activity during the Late Noachian and Early Hesperian (e.g., Head et al., 2001). Otherwise, a dry crustal rheology is hardly consistent with the comparison among the evolution of effective elastic thickness of the lithosphere and the thermal history models for Mars (Guest and Smrekar, 2007; Grott and Breuer, 2007).

By equating the brittle and ductile strength for $z=z_{\mathrm{BDT}}$ (where $z_{\mathrm{BDT}}$ is the depth to the brittle-ductile transition) the temperature
$T_{\mathrm{BDT}}$ at the brittle-ductile transition can be obtained. This permits the determination of the surface heat flow solving from Eq. (1),

$F=\frac{k_{\mathrm{c}}\left(T_{\mathrm{BDT}}-T_{\mathrm{s}}\right)}{z_{\mathrm{BDT}}}+\frac{z_{\mathrm{BDT}} H}{2}$.

From Eq. (5) it is clear that the determination of the surface heat flow from the brittle-ductile transition depth does not depend on the total crustal thickness. Fig. 5 shows the surface heat flow deduced from the depth of faulting beneath Amenthes Rupes, as a function of the brittle-ductile transition depth and strain rate. For $z_{\mathrm{BDT}}=27-35 \mathrm{~km}$, the heat flow is $26-37 \mathrm{~mW} \mathrm{~m}^{-2}$.

Previous works calculating Martian heat flows from effective elastic thicknesses or brittle-ductile transition depths were performed by using linear thermal gradients (with the exception of Ruiz et al., 2006a,b), which is equivalent to take $H=0$ in Eq. (5). Surface heat flows obtained from the depth to the brittleductile transition increases if crustal heat sources are taken into account (Ruiz et al., 2006b; Ruiz, 2007). So, for comparative purposes, we have calculated thermal gradients and heat flows for zero crustal heat production rate. For $z_{\mathrm{BDT}}=27-35 \mathrm{~km}$, we obtain thermal gradients of $9-14 \mathrm{~K} \mathrm{~km}^{-1}$ and heat flows of $18-29 \mathrm{~mW}$ $\mathrm{m}^{-2}$. The work by Schultz and Watters (2001) obtained a heat flow of $\sim 54-70 \mathrm{~mW} \mathrm{~m}^{-2}$ for a faulting depth of $30 \mathrm{~km}$ beneath Amenthes Rupes. These authors used linear thermal gradients, a thermal conductivity of $3.2 \mathrm{~W} \mathrm{~m}^{-1} \mathrm{~K}^{-1}$, and temperatures of $725-875 \mathrm{~K}$ at the depth of faulting. Re-scaling their values for the crustal thermal conductivity used in this work the heat flow would be $34-44 \mathrm{~mW} \mathrm{~m}^{-2}$, which still is higher than our results for $H=0$. The discrepancy is due to the higher temperature values assumed for the depth of faulting by Schultz and Watters (2001). These higher temperatures are based on the relation between effective elastic thicknesses and temperature profiles of the oceanic lithosphere (e.g., Watts, 2001), which integrates the crust and lithospheric mantle and, as a whole, is stronger than the basaltic crust. For diabase rheology, however, we obtain temperatures at the brittle-ductile transition between $\sim 530 \mathrm{~K}$ and $\sim 610 \mathrm{~K}$, depending on strain rate and (at lesser proportion) crustal density and depth of faulting. Our thermal gradients for $H=0$ are similar

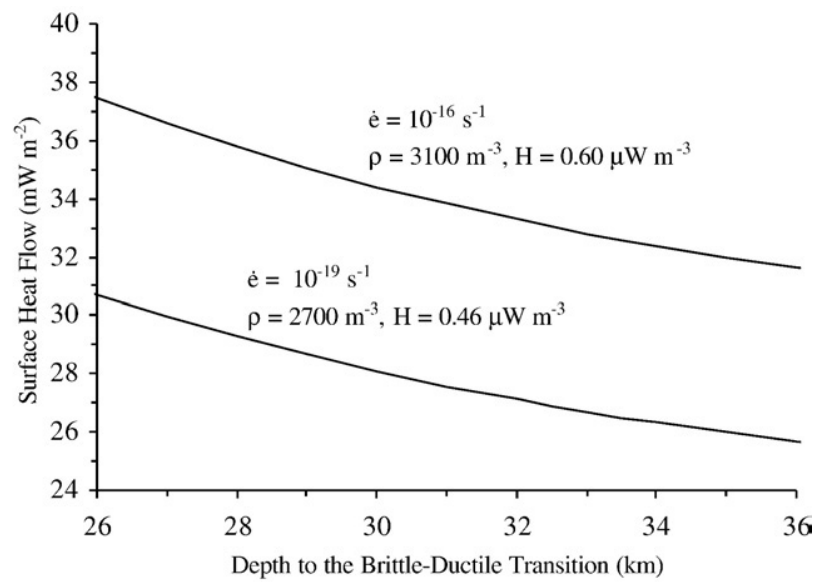

Fig. 5. Surface heat flow as a function of the depth to the brittle-ductile transition and strain rate calculated for the time when Amenthes Rupes was formed. 
to the values obtained for two lobate scarps in the Thaumasia region by Grott et al. (2007), and to those deduced from the effective elastic thickness of Noachian/Hesperian features (McGovern et al., 2004).

The heat flows in Fig. 5, combined with the heat dissipation rate, can be used to place an upper limit on the local crustal thickness. The crustal contribution to the surface heat flow is given by $H b$, whereas the remainder must reach the crust from the mantle (see Section 2). Thus, an upper limit on the crustal thickness is imposed by the condition of non-negative mantle heat flow. This upper limit varies depending on the brittle-ductile transition depth, strain rate, crustal density and heat production rate, and it ranges from 47 to $76 \mathrm{~km}$ for $z_{\mathrm{BDT}}=27-35 \mathrm{~km}$. According to the crustal model in Neumann et al. (2004), the crustal thickness in the Amenthes region ranges between $\sim 0$ and $\sim 5 \mathrm{~km}$ greater than the average crustal thickness of Mars, fixed at $45 \mathrm{~km}$. Our results, therefore, indicate that the average crustal thickness is less than $\sim 75 \mathrm{~km}$, which is consistent with the estimation of between 38 and $62 \mathrm{~km}$ proposed by Wieczorek and Zuber (2004).

\section{The effective elastic thickness of the lithosphere in the Amenthes region}

The present-day topography of the Amenthes region was most probably established during the Late Noachian to Early Hesperian, since it is the time range estimated for the significant tectonic modification observed near the dichotomy boundary that separates the northern lowlands from the southern highlands (Watters, 2003a; Watters and McGovern, 2006). This is independent of the original dichotomy formational mechanism (s), which was probably active in a much earlier phase of Mars' evolution (e.g., Frey, 2006). As the effective elastic thickness of the lithosphere refers to the state when the topography was established, this parameter can then be calculated for approximate time of thrust fault formation in this region.

For the Amenthes region or their surroundings, the calculation of the effective elastic thickness has been attempted in several ways. The present-day topography of the dichotomy boundary east of the Amenthes region is consistent with flexure of the highlands (possibly due to loading of the lowlands by massive volcanic deposits), and an effective elastic thickness between $\sim 30$ and $\sim 36 \mathrm{~km}$, depending on the assumed densities and elastic parameters (Watters, 2003a; Watters and McGovern, 2006).

The modeling of the gravity field of an area including Amenthes Rupes by Kiefer (2005) has resulted in an effective elastic thickness lower than $25 \mathrm{~km}$ with a best fit of $0 \mathrm{~km}$ (Kiefer, 2005). These low values could be related to the large portion of Noachian-age southern cratered highland terrain included in the analyzed area (as pointed out by Milbury et al., 2007), as they are similar to those found elsewhere in the southern highlands (McGovern et al., 2002, 2004; Grott et al., 2005; Kronberg et al., 2007).

On the other hand, the admittance modeling of the Amenthes region by Milbury et al. (2007) has found an effective elastic thickness of $\sim 15-35 \mathrm{~km}$ (specifically $14-36 \mathrm{~km}$, with a best fit value of $30 \mathrm{~km}$, after their Fig. 4). The results of this study are relatively independent of the assumed densities for crust and mantle, although they can be influenced by the inclusion of a substantial portion of the northern lowlands in the analyzed area, whose admittance signature may mark the state of the lithosphere at different times and geologic provinces. Indeed, these authors obtained a crustal thickness of $15-40 \mathrm{~km}$ for this area, a value similar to those proposed for the lowlands but excessively thin for the highlands (which are $\sim 60 \mathrm{~km}$ thick, in average, in the crustal model of Neumann et al. (2004)). That work used a slightly lower value for the Young's modulus than the value used in this work, which in turn implies somewhat lower effective elastic thickness values when our preferred value is used. In this case, the upper limit in the Fig. 4 of Milbury et al. (2007) should approach $35 \mathrm{~km}$, a value similar to that deduced from flexure of the southern cratered highlands at the dichotomy boundary.

We have performed an independent calculation of the effective elastic thickness in this region for a topography profile from $246.9^{\circ} \mathrm{W}\left(113.10^{\circ} \mathrm{E}\right), 9.6^{\circ} \mathrm{S}$ to $228.9^{\circ} \mathrm{W}\left(131.1^{\circ} \mathrm{E}\right), 17.3^{\circ} \mathrm{N}$ (see location in Fig. 1), using a coherence analysis of topography and gravity spectra (e.g., Forsyth, 1985), which was done by means of the multitaper spectral technique (for a detailed description of this methodology see Simons et al., 2000). The effective elastic thickness is obtained by comparison of the observed coherence (the analogue of correlation in the wavenumber domain), estimated from gravity and topography, with the coherence theoretically predicted as a function of $T_{\mathrm{e}}$. Topography must be fully compensated by Moho deflection at long wavelengths (coherence equal to 1), whereas at short wavelengths it is compensated by the flexural rigidity of the lithosphere without any Moho deflection (coherence equal to 0 ). The wavelength at which the transition between low and high coherence values occurs is directly related to the effective elastic thickness of the lithosphere. The explicit relation between transitional wavelength, internal to surface loading ratio and effective elastic thickness has been derived by Simons and van der Hilst (2003).

The multitaper technique is used here to calculate the power spectral density function (Thomson, 1982), and provides an optimal spectrum estimate by minimizing spectral leakage while reducing the variance of the estimate by averaging orthogonal eigenspectrum determinations (Lees and Park, 1995). In order to do this, ideal data windows need to be obtained, whose spectral responses have the narrowest central lobe and the smallest possible sidelobe level. These ideal data windows are given by prolate spheroidal sequences (Slepian, 1978). The parameter NW, which usually varies from 2 to 4 , determines the resolution of the coherence estimations (Simons et al., 2000).

We have used the same elastic constants values as in Section 3, surface load and mantle densities of 2900 and $3500 \mathrm{~kg} \mathrm{~m}^{-3}$ respectively, MOLA $1 / 128^{\circ}$ gridded topography, and Bouguer anomaly (Neumann et al., 2004), and we assume a constant internal to surface loading ratio equal to 1 for every wavenumber. In order to reduce the profile's noise, a radial averaging of the coherence function has been applied to obtain a smoothed 
representation of the observed coherence versus wavelength. We obtain, by minimizing the RMS error between the observed and theoretical coherence, best fit effective elastic thicknesses between 19 and $25 \mathrm{~km}$ (Fig. 6a). Fig. 6b shows the observed coherence compared with the theoretical curve for an effective

a)
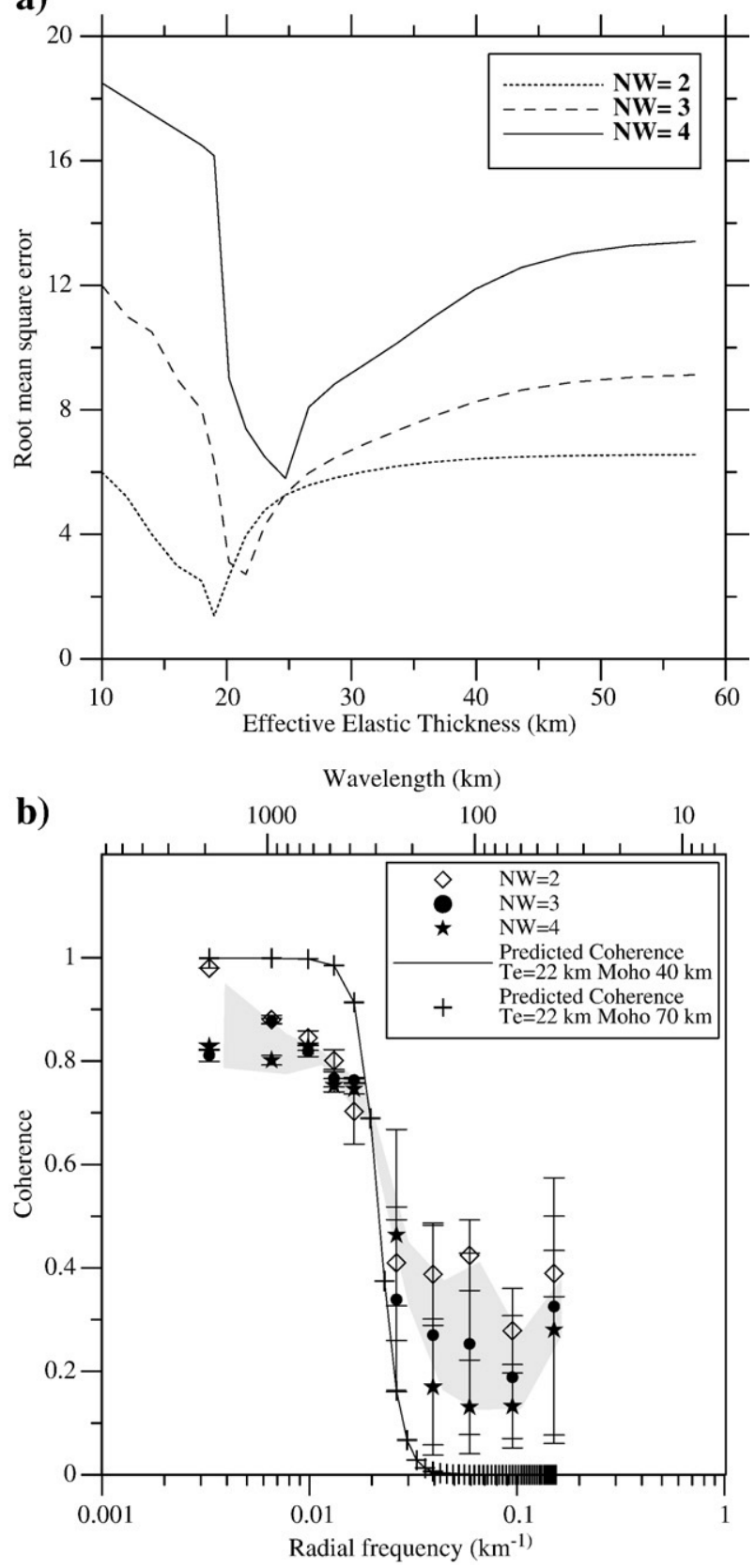

Fig. 6. a) RMS error between the observed and theoretical coherence for three values of $\mathrm{NW}$, the parameter that determines the resolution of the estimations (see the text for more details). b) Coherence analysis of the topography and gravity spectra along the profile shown in Fig. 1, performed by means of the multitaper spectral technique. Open diamonds, black circles and black stars indicate the observed coherence for $\mathrm{NW}=2,3$ and 4 respectively; the gray area contains the central values of the observed coherence for these three NW values. Solid line and crosses indicate the predicted coherence, calculated for $T_{\mathrm{e}}=22 \mathrm{~km}$, for Moho depths of 40 and $70 \mathrm{~km}$ respectively. elastic thickness of $22 \mathrm{~km}$. For long wavelengths, the observed coherence is lower than the predicted one. This effect has been previously described (e.g. Simons et al., 2000), and can be attributed to several factors, such as the differences between the starting model and the real crustal structure, or the difficulty in reducing the uncertainty in the relationship between internal and top loads. It can also be observed that theoretical coherence curves do not show any appreciable variation for crustal thicknesses of $40 \mathrm{~km}$ [value similar to the lower limit proposed by Wieczorek and Zuber (2004) for the average thickness of the Martian crust] and $70 \mathrm{~km}$ (roughly the upper limit found for the Amenthes region in Section 3), which implies that the obtained effective elastic thickness values are nearly independent of the crustal thickness used in the calculations.

Some authors have suggested that the multitaper method can underestimate the effective elastic thickness (e.g., Ojeda and Whitman, 2002; Swain and Kirby, 2003). For this reason, we took our result as a lower limit. Thus, considering the diverse estimations available, $19-35 \mathrm{~km}$ is a conservative range for the effective elastic thickness of the lithosphere of the Amenthes region at the time when the observed topography was formed. These values are higher than the effective elastic thicknesses obtained for Noachian regions (e.g., McGovern et al., 2004), which support that the present-day topography of the Amenthes region was established roughly simultaneously to the Late Noachian/Early Hesperian tectonic modification of this region.

\section{Heat flow from the effective elastic thickness}

The effective elastic thickness is a measure of the total strength of the lithosphere, which integrates contributions from brittle and ductile layers and from the elastic cores of the lithosphere (for reviews see Watts and Burov, 2003). Effective elastic thicknesses can be converted to heat flows following the equivalent strength envelope procedure described by McNutt (1984). This methodology is based on the condition that the bending moment of the mechanical lithosphere must be equal to the bending moment of the equivalent elastic layer of thickness $T_{\mathrm{e}}$. The bending moment of the mechanical lithosphere is estimated from its strength envelope and from the curvature of the elastic layer: the link to heat flow comes from the dependence of the ductile strengths on the temperature profile.

The bending moment of a purely elastic plate is

$M=\frac{E K T_{\mathrm{e}}^{3}}{12\left(1-v^{2}\right)}$,

where $E$ is the Young's modulus, $K$ is the topography curvature, $T_{\mathrm{e}}$ is the effective elastic thicknesses, and $v$ is the Poisson's ratio. The bending moment of a mechanical lithosphere with one brittle layer and one ductile layer is given by

$M=\int_{0}^{T_{\mathrm{m}}} \sigma(z)\left(z-z_{\mathrm{n}}\right) d z$,

where $T_{\mathrm{m}}$ is the mechanical thickness of the lithosphere, $\sigma(z)$ is the least, at depth $z$, of the brittle strength, the ductile strength, or the fiber stress, and $z_{\mathrm{n}}$ is the depth to the neutral stress plane. 
Brittle and ductile strengths are given by Eqs. (3) and (4), and the fiber stress is calculated from the expression

$\sigma_{\mathrm{fib}}=\frac{E K\left(z-z_{\mathrm{n}}\right)}{1-v^{2}}$.

Additionally, the condition of zero net axial force is imposed,

$\int_{0}^{T_{\mathrm{m}}} \sigma(z) d z=0$.

The strength envelope procedure for a rheologically stratified lithosphere, with several brittle and ductile layers, is more complicated (see, for example, McNutt et al., 1988; Burov and Diament, 1992, 1995; Ruiz et al., 2006b,c). In the case of a lithosphere with mechanically decoupled crust and mantle, the total bending moment is given by

$M=M_{\text {crust }}+M_{\text {mantle }}$,

where the subindex refers to the crust and lithospheric mantle contributions to the total bending moment. In addition, the condition of zero net axial force must be imposed to both the crust and lithospheric mantle. (For a more detailed description of the application of this procedure to a lithosphere with mechanically decoupled crust and mantle see Ruiz et al., 2006c.).

The base of the mechanical lithosphere is defined as the depth at which the strength reaches a low value, and below which there are no further significant increases in strength (e.g., McNutt, 1984; Ranalli, 1997); here we use a value of $50 \mathrm{MPa}$ (McNutt, 1984), but the exact selected value does not produce significant changes in the calculations due to the exponential dependence of ductile strength on temperature. Whereas the strength at the top of the mantle is above $50 \mathrm{MPa}$, we consider a rheologically stratified lithosphere with contributions to the total bending moment (and hence to the effective elastic thickness) from the crust and lithospheric mantle. If the strength at the top of the mantle is under $50 \mathrm{MPa}$, only the crustal contribution is considered. On the other hand, if the strength at the base of the crust is high enough the crust would be welded to the mantle's top, which would increase the total strength of the lithosphere. In this case, a higher heat flow is needed to achieve a given effective elastic thickness value. This possibility is not considered here, because all of our calculations obtain that the strength of the base of the crust is lower than $50 \mathrm{MPa}$. We will return to this point later.

Brittle and ductile crustal strengths are calculated as in Section 3. The brittle strength of the lithospheric mantle is calculated for a density of $3500 \mathrm{~kg} \mathrm{~m}^{-3}$, starting from the brittle strength at the base of the crust. The ductile strength of the lithospheric mantle is calculated for dry and wet olivine dislocation creep rheologies. For wet olivine, we use the flow law of the Anita Bay dunite: $A=9550 \mathrm{MPa}^{-n} \mathrm{~s}^{-1}, n=3.35$ and $Q=444 \mathrm{~kJ} \mathrm{~mol}^{-1}$ (Chopra and Paterson, 1984). This flow law places a lower limit on the strength of wet olivine due to its relative weakness (compared with other wet dunites, such as Aheim dunite). For dry olivine we use the flow law obtained for artificially dried dunites (which is valid for both Anita Bay and
Aheim dunites): $A=28840 \mathrm{MPa}^{-n} \mathrm{~s}^{-1}, n=3.6$ and $Q=535 \mathrm{~kJ}$ $\mathrm{mol}^{-1}$ (Chopra and Paterson, 1984). Strain rates of $10^{-16}$ and $10^{-19} \mathrm{~s}^{-1}$ are used for consistency with calculations in Section 3. For the calculation of fiber stress the elastic parameters are taken as $E=100 \mathrm{GPa}$ and $v=0.25$ for both the crust and lithospheric mantle, while the topography curvature, obtained from the maximum value of the second derivative of the regional topography in the profile indicated in Fig. 1 , is $2 \times 10^{-7} \mathrm{~m}^{-1}$.

Fig. 7 shows upper and lower limits for the surface heat flow deduced from the effective elastic thickness as functions of the crustal thickness. Also represented is the contribution from radiogenic heat sources in the crust, which marks the maximum crustal thickness permitted by the condition of non-negative mantle heat flow. The upper limits correspond to $T_{\mathrm{e}}=19 \mathrm{~km}$, $\dot{e}=10^{-16} \mathrm{~s}^{-1}, \rho=3100 \mathrm{~kg} \mathrm{~m}^{-3}, H=0.60 \mu \mathrm{W} \mathrm{m}^{-3}$, and a dry olivine rheology; for crustal thicknesses above $58 \mathrm{~km}$, the strength at the top of the mantle is under $50 \mathrm{MPa}$, and therefore only crustal strength is considered. The lower limits correspond to $T_{\mathrm{e}}=35 \mathrm{~km}, \dot{e}=10^{-19} \mathrm{~s}^{-1}, \rho=2700 \mathrm{~kg} \mathrm{~m}^{-3}, H=0.46 \mu \mathrm{W} \mathrm{m}{ }^{-3}$, and a wet olivine rheology; in this case, the strength at the top of the mantle is always above $50 \mathrm{MPa}$.

On the basis of the relatively low gravity of Mars it can be argued that the strength level used to define the base of the mechanical crust should be lower for Mars than for Earth (for example, $10 \mathrm{MPa}$ instead $50 \mathrm{MPa}$; Ruiz et al., 2006a). Higher strength levels at the base of the crust are favored for low heat flows, low crustal thickness and high strain rates. But a crust mechanically welded to the upper mantle implies, in turn, a higher heat flow necessary to achieve a given value of the effective elastic thickness. Thus, the decoupled case is useful to put a lower limit to the calculated heat flow. Moreover, we find that only for the cases studied with higher effective elastic thicknesses, low crustal thicknesses $\left(<55 \mathrm{~km}\right.$ for $\left.e=10^{-16} \mathrm{~s}^{-1}\right)$, and wet mantle rheology, the strength at the base of the crust can be above $10 \mathrm{MPa}$, although never above $\approx 30 \mathrm{MPa}$.

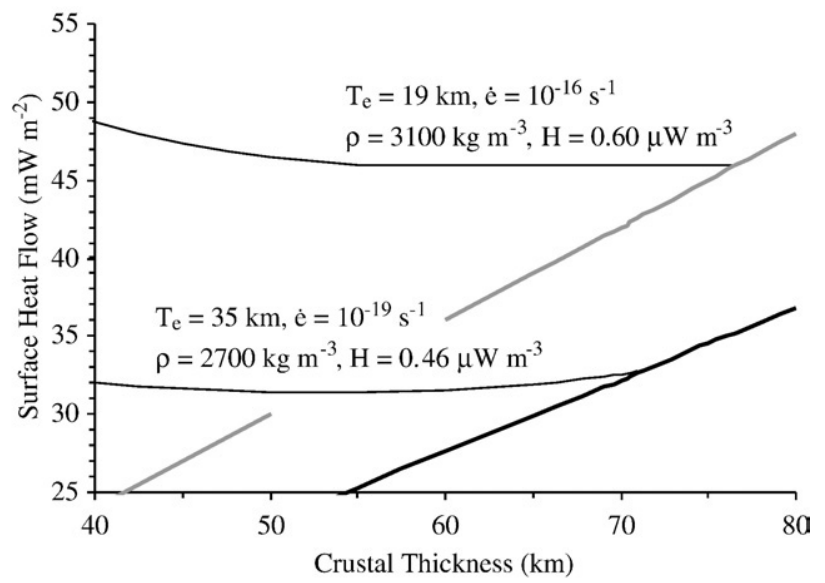

Fig. 7. Upper and lower limits for the surface heat flow deduced from the effective elastic thickness shown as functions of the crustal thickness. Also represented are the upper and lower limits for the contributions to the heat flow coming from radiogenic heat sources in the crust (gray bold line for $\rho=3100 \mathrm{~kg} \mathrm{~m}^{-3}$ and $H=0.60 \mu \mathrm{W} \mathrm{m}{ }^{-3}$, and black bold line for $\rho=2700 \mathrm{~kg} \mathrm{~m}^{-3}$ and $H=0.46 \mu \mathrm{W} \mathrm{m}^{-3}$ ), which marks the maximum crustal thickness permitted by the condition of nonnegative mantle heat flow. 
The obtained heat flows range from 31 to $49 \mathrm{~mW} \mathrm{~m}^{-2}$. These values are generally higher than those calculated from the depth to the brittle-ductile transition. The implications of this result are analyzed in the following section.

\section{Conclusions: Putting it all together}

An important result presented in the previous section is that heat flows obtained for the Amenthes region from the effective elastic thickness are generally higher than those deduced from the depth to the brittle-ductile transition. In fact, we can obtain additional constraints on crustal thickness and thermal and rheological structure of the lithosphere at the Late Noachian/ Early Hesperian, through the analysis of the overlapping between $T_{\mathrm{e}}$ - and $z_{\mathrm{BDT}}$-based heat flows.

Fig. 8 ompares, for strain rates of $10^{-19}$ and $10^{-16} \mathrm{~s}^{-1}$, heat flows calculated for $T_{\mathrm{e}}=35 \mathrm{~km}$ and dry and wet mantle rheologies with those obtained for $z_{\mathrm{BDT}}=27 \mathrm{~km}$ (which are not dependent on mantle rheology); in these calculations $\rho=2700 \mathrm{~kg} \mathrm{~m}^{-3}$ and
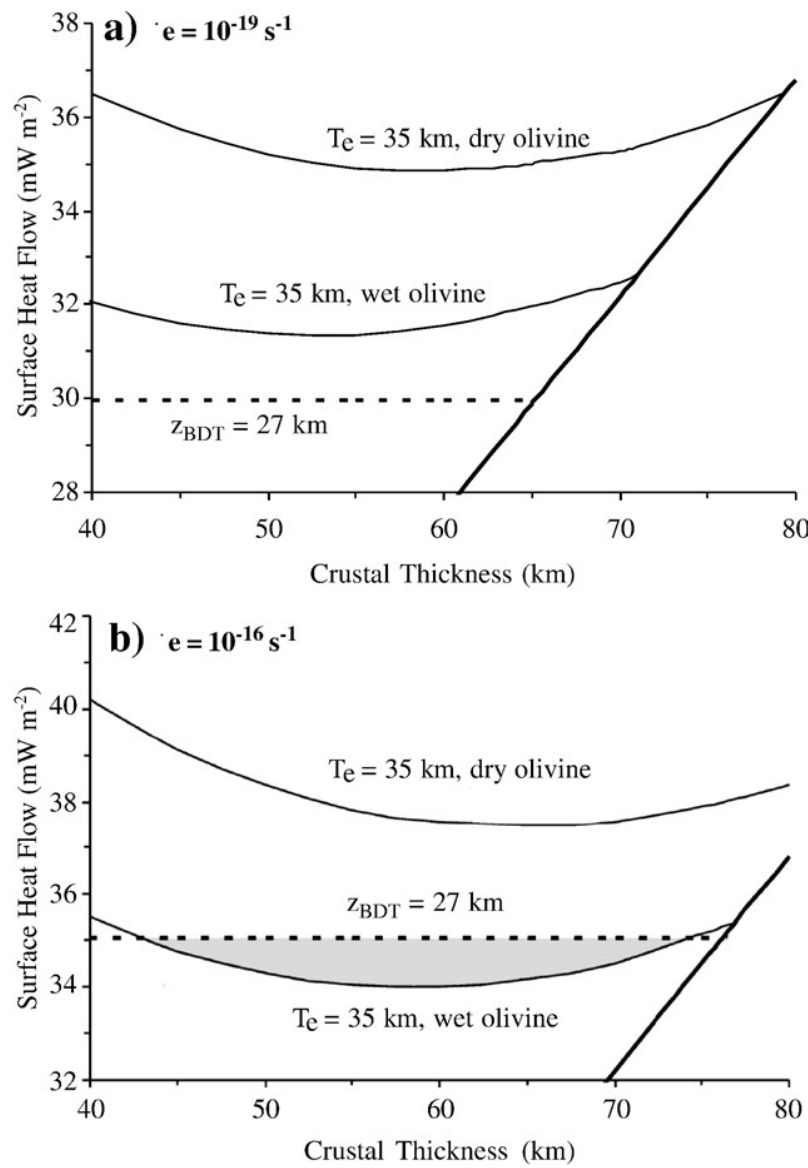

Fig. 8. Lower limits of the heat flow obtained from the effective elastic thickness, as a function of crustal thickness and lithospheric mantle rheology, compared with upper limits obtained from the depth to the brittle-ductile transition (dashed lines), for strain rates of (a) $10^{-19}$ and (b) $10^{-16} \mathrm{~s}^{-1}$. The calculations have been performed for $\rho=2700 \mathrm{~kg} \mathrm{~m}^{-3}$ and $H=0.46 \mu \mathrm{W} \mathrm{m}{ }^{-3}$. Also represented is the contribution to the heat flow arising from radiogenic heat sources in the crust (bold solid line), which marks the maximum permitted crustal thickness. The grey area in Fig. $8 \mathrm{~b}$ shows the overlap between $T_{\mathrm{e}}$ - and $z_{\mathrm{BDT}}$-based heat flow calculations.

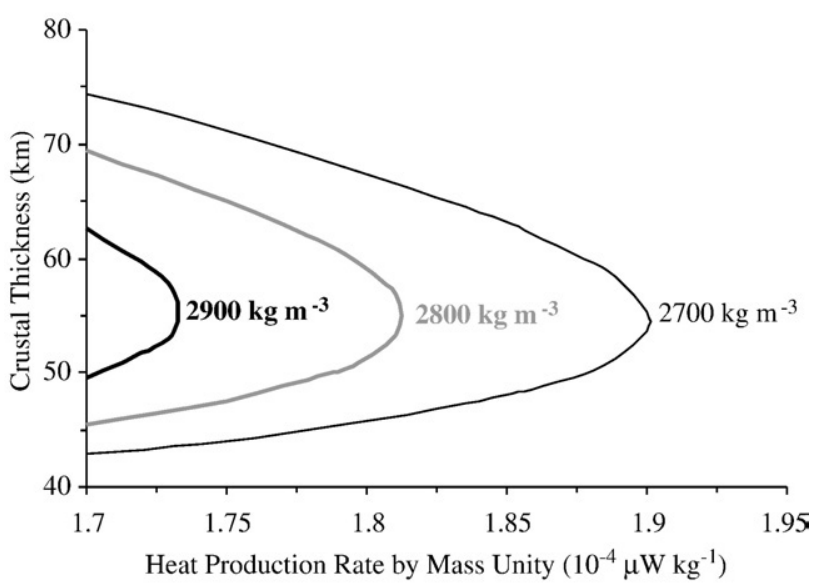

Fig. 9. Crustal thicknesses for which $T_{\mathrm{e}}$ - and $z_{\mathrm{BDT}}$-based heat flows are equal, for wet mantle rheology and $e=10^{-16} \mathrm{~s}^{-1}$, as a function of the heat production rate by mass unity and crustal density.

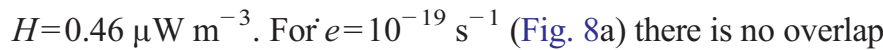
between $T_{\mathrm{e}^{-}}$and $z_{\mathrm{BDT}}$-based heat flows. For $e=10^{-16} \mathrm{~s}^{-1}$ (Fig. 8b) there is a relatively limited overlap for a wet mantle rheology. Fig. 9 shows the crustal thicknesses for which $T_{\mathrm{e}^{-}}$and $z_{\mathrm{BDT}}$-based heat flows overlap for wet mantle rheology and $e=10^{-16} \mathrm{~s}^{-1}$, as a function of the heat production rate by mass unity $(H / \rho)$ and crustal density; in this figure we use heat production rates normalized by mass unity in order to improve graphical comparison for different densities. The overlap for wet mantle rheology is reduced, or even disappeared, when increasing the crustal density or heat production rate (the maximum overlap corresponds to the case represented in Fig. 8b). On the other hand, there is no overlap for any case using a dry mantle rheology: our results are therefore clearly inconsistent with a dry olivine rheology for the lithospheric mantle.

Our results limit the brittle-ductile transition depth to be no shallower than $29 \mathrm{~km}$, which is consistent with the faulting depth obtained for Amenthes Rupes by both Schultz and Watters (2001)

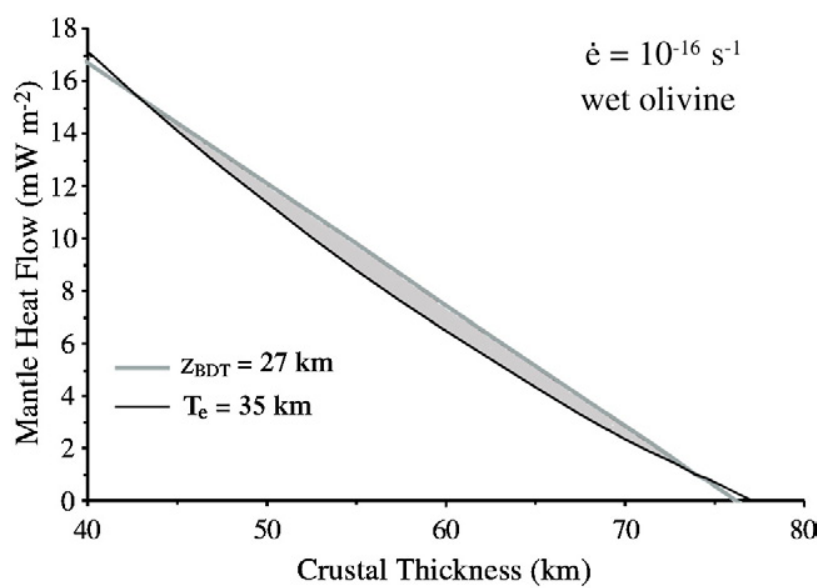

Fig. 10. Comparison of mantle heat flow values calculated for $z_{\mathrm{BDT}}=27 \mathrm{~km}$ (gray bold line), with those obtained for $T_{\mathrm{e}}=35 \mathrm{~km}$ and wet mantle rheology (black line), as a function of crustal thickness. The calculations have been performed for $\rho=2700 \mathrm{~kg} \mathrm{~m}^{-3}$ and $H=0.46 \mu \mathrm{W} \mathrm{m}{ }^{-3}$. The grey area shows the overlap between $T_{\mathrm{e}}$ and $z_{\mathrm{BDT}}$-based heat flow calculations. 
and this work (see Section 3). Similarly, the effective elastic thickness cannot be lower than $28 \mathrm{~km}$, which is consistent with the results obtained from flexure (Watters, 2003a; Watters and McGovern, 2006) and admittance studies (Milbury et al., 2007). Our result suggest a surface heat flow of $31-36 \mathrm{~mW} \mathrm{~m}^{-2}$, a wet mantle rheology, and a crustal thickness of $43-74 \mathrm{~km}$, for the Amenthes region at the Late Noachian/Early Hesperian time. The density of the crust should not be higher than $\approx 2950 \mathrm{~kg} \mathrm{~m}^{-3}$, and higher strain rates are favored.

A wet lithospheric mantle rheology is consistent with the results based on comparative analyses between the evolution of effective elastic thickness through time and the thermal history models for Mars (Guest and Smrekar, 2007; Grott and Breuer, 2007). As the thickness of the crust in this region is $\sim 0-5 \mathrm{~km}$ thicker than the average planetary value (Neumann et al., 2004), our results suggest an average thickness of $\sim 40-75 \mathrm{~km}$ for the Martian crust, which is consistent with the range of $38-62 \mathrm{~km}$ obtained by Wieczorek and Zuber (2004) from geophysical and geochemical arguments. For the nominal crustal density of $2900 \mathrm{~kg} \mathrm{~m}^{-3}$ used by Neumann et al. (2004), our results suggest a crustal thickness of $50-63 \mathrm{~km}$ for the Amenthes region, and an average crustal thickness of $\sim 45-65 \mathrm{~km}$ for Mars.

Fig. 10 compares mantle heat flows obtained for $T_{\mathrm{e}}=35 \mathrm{~km}$ and wet mantle rheology with those obtained for $z_{\mathrm{BDT}}=27 \mathrm{~km}$, calculated using $\dot{e}=10^{-16} \mathrm{~s}^{-1}, \rho=2700 \mathrm{~kg} \mathrm{~m}^{-3}$ and $H=0.46 \mu \mathrm{W} \mathrm{m}{ }^{-3}$ (case equivalent to Fig. $8 \mathrm{~b}$ ), values maximizing the overlap between $T_{\mathrm{e}^{-}}$and $z_{\mathrm{BDT}}$-based results. The overlap corresponds to mantle heat flows between 1 and $15 \mathrm{~mW}$ $\mathrm{m}^{-2}$, and the fraction of the surface heat flow originated from crustal heat sources is $0.56-0.98$. The low mantle heat flow, compared with that predicted by mantle convection models for Mars (e.g. Hauck and Phillips, 2002), could be a local (and maybe temporal) phenomenon. Alternatively, the emplacement of a substantial fraction of radioactive heat sources in the crust could have influenced mantle convection, making it more sluggish and decreasing convective heat flow (see Reese et al., 1998).

Surface temperatures could have been higher in the early Mars (e.g., Fanale et al., 1992). In this case, heat flows for the Amenthes region would have been lower than those derived in this work. The overlap between $T_{\mathrm{e}}$ - and $z_{\mathrm{BDT}}$-based values would also have been reduced, and for $T_{\mathrm{s}}>243 \mathrm{~K}$ the overlap does not exist. So, this overlap requires surface temperatures well below the water freezing point, and close to the present-day values. This is in accordance with the low near-surface temperatures deduced for most of the past $4 \mathrm{Ga}$ from ALH84001 thermochronology (Shuster and Weiss, 2005).

In summary, estimations of both the depth to the crustal brittle-ductile transition and the effective elastic thickness of the lithosphere for the Amenthes region permit two sets of independent heat flow calculations for similar epochs, which should (at least roughly) be consistent. This, joined with estimations of radioactive heat production in the crust, has permitted us to sharply constrain surface and mantle heat flow, lithospheric mantle rheology and crustal thickness for the Amenthes region during the Late Noachian/Early Hesperian time.

\section{Acknowledgements}

The authors thank the useful comments and suggestions from two anonymous reviewers. JR was supported by a contract I3P with the CSIC, co-financed from the European Social Fund.

\section{References}

Anderson, S., Grimm, R.E., 1998. Rift processes at the Valles Marineris, Mars: constraints from gravity on necking and rate-depending strength evolution. J. Geophys. Res. 103, 11,113-11,124.

Bertka, C.M., Fei, Y., 1998a. Density profile of a SNC model Martian interior and the moment-of-inertia factor of Mars. Earth Planet. Sci. Lett. 157, 79-88.

Bertka, C.M., Fei, Y., 1998b. Implications of Mars Pathfinder data for the accretion history of the terrestrial planets. Science 281, 1838-1840.

Bonner, J.L., Blackwell, D.D., Herrin, E.T., 2003. Thermal constraints on earthquake depths in California. Bull. Seismol. Soc. Am. 93, 2333-2354.

Burov, E.B., Diament, M., 1992. Flexure of the continental lithosphere with multilayered rheology. Geophys. J. Int. 109, 449-468.

Burov, E.B., Diament, M., 1995. The effective elastic thickness $\left(\mathrm{T}_{\mathrm{e}}\right)$ of continental lithosphere: what does it really mean? J. Geophys. Res. 100, 3905-3927.

Caristan, Y., 1982. The transitions from high temperature creep to fracture in Marylan diabase. J. Geophys. Res. 87, 6781-6790.

Chopra, P.N., Paterson, M.S., 1984. The role of water in the deformation of dunite. J. Geophys. Res. 89, 7861-7876.

Clifford, S.M., 1993. A model for the hydrologic and climatic behaviour of water on Mars. J. Geophys. Res. 98, 10973-11016.

Fanale, F.P., Postawko, S.E., Pollack, J.B., Carr, M.H., Pepin, R.O., 1992. Mars: epochal climate change and volatile history. In: Kieffer, H.H., Jakosky, B.M., Snyder, C.W., Matthews, M.S. (Eds.), Mars. University of Arizona Press, Tucson, pp. 1135-1179.

Forsyth, D.W., 1985. Subsurface loading and estimates of the flexural rigidity of continental lithosphere. J. Geophys. Res. 90, 12623-12632.

Frey, H.V., 2006. Impact constraints on, and a chronology for, major events in early Mars history. J. Geophys. Res. 111. doi:10.1029/2005JE002449 E08S91.

Grott, M., Breuer, D., 2007. The evolution of the Martian elastic lithosphere and implications for crustal and mantle rheology. Icarus 186, 517-526.

Grott, M., Hauber, E., Werner, S.C., Kronberg, P., Neukum, G., 2005. High heat flux on ancient Mars: evidence from rift flank uplift at Coracis Fossae. Geophys. Res. Lett. 32. doi:10.1029/2005GL023894 L21201.

Grott, M., Hauber, E., Werner, S.C., Kronberg, P., Neukum, G., 2007. Mechanical modelling of thrust faults in the Thaumasia region, Mars, and implications for the Noachian heat flux. Icarus 186, 517-526.

Guest, A., Smrekar, S., 2007. New constraint on the thermal and volatile evolution of Mars. Physics Earth Planet. Interiors 164, 161-176.

Hartmann, W.K., Neukum, G., 2001. Cratering chronology and the evolution of Mars. Space Sci. Rev. 96, 165-194.

Hauck, S.A., Phillips, R.J., 2002. Thermal and crustal evolution of Mars. J. Geophys. Res. 107. doi:10.1029/2001JE001801.

Head, J.W., Greeley, R., Golombek, M.P., Hartmann, W.K., Hauer, E., Jaumann, R., Masson, P., Neukum, G., Nyquist, L.E., Carr, M.H., 2001. Geological processes and evolution. Space Sci. Rev. 96, 263-292.

Kiefer, W.S., 2004. Gravity evidence for an extinct magma chamber beneath Syrtis Major, Mars: a look at the magmatic plumbing system. Earth Planet. Sci. Lett. 222, 349-361.

Kiefer, W.S., 2005. Buried mass anomalies along the hemispheric dichotomy in eastern Mars: implications for the origin and evolution of the dichotomy. Geophys. Res. Lett. 32. doi:10.1029/2005GL024260 L22201.

Kieffer, H.H., Martin, T.Z., Peterfreund, A.R., Jakosky, B.M., Miner, E.D., Palluconi, F.D., 1977. Thermal and albedo mapping of Mars during the Viking primary mission. J. Geophys. Res. 82, 4249-4291.

Kronberg, P., Hauber, E., Grott, M., Werner, S.C., Schäfer, T., Gwinner, K., Giese, B., Masson, P., Neukum, G., 2007. Acheron Fossae, Mars: tectonic rifting, volcanism, and implications for lithospheric thickness. J. Geophys. Res. 112. doi:10.1029/2002JE001854 E04005. 
Lees, J.M., Park, J., 1995. Multiple-taper spectral analysis: a stand-alone C-subroutine. Comput. Geosci. 21, 199-236.

Lin, J., Stein, R.S., 2004. Stress triggering in thrust and subduction earthquakes, and stress interaction between the southern San Andreas and nearby thrust and strike-slip faults. J. Geophys. Res. 109. doi:10.1029/2003JB002607 B02303.

McGovern, P.J., Solomon, S.C., Smith, D.E., Zuber, M.T., Simons, M., Wieczorek, M.A., Phillips, R.J., Neumann, G.A., Aharonson, O., Head, J.W., 2002. Localized gravity/topography admittance and correlation spectra on Mars: implications for regional and global evolution. J. Geophys. Res. 107. doi:10.1029/2002JE001854 5136.

McGovern, P.J., Solomon, S.C., Smith, D.E., Zuber, M.T., Simons, M., Wieczorek, M.A., Phillips, R.J., Neumann, G.A., Aharonson, O., Head, J.W., 2004. Correction to localized gravity/topography admittance and correlation spectra on Mars: implications for regional and global evolution. J. Geophys. Res. 109. doi:10.1029/2004JE002286 E07007.

McLennan, S.M., 2001. Crustal heat production and the thermal evolution of Mars. Geophys. Res. Lett. 28, 4019-4022.

McLennan, S.M., 2003. Large-ion lithophile element fractionation during the early differentiation of Mars and the composition of the martian primitive mantle. Meteor. Planet. Sci. 38, 895-904.

McNutt, M.K., 1984. Lithospheric flexure and thermal anomalies. J. Geophys. Res. 89, 11180-11194.

McNutt, M.K., Diament, M., Kogan, M.G., 1988. Variations of elastic plate thickness at continental thrust belts. J. Geophys. Res. 93, 8825-8838.

Milbury, C.A.E., Smrekar, S.E., Raymond, C.A., Schubert, G., 2007. Lithospheric structure in the eastern region of Mars' dichotomy boundary. Planet. Space Sci. 55, 280-288.

Neumann, G.A., Zuber, M.T., Wieczorek, M.A., McGovern, P.J., Lemoine, F.G., Smith, D.E., 2004. The crustal structure of Mars from gravity and topography. J. Geophys. Res. 109. doi:10.1029/2004JE002262 E08002.

Nimmo, F., 2002. Admittance estimates of mean crustal thickness and density at the Martian hemispheric dichotomy. J. Geophys. Res. 107. doi:10.1029/ 2000JE001488 5117.

Nimmo, F., Stevenson, D.J., 2001. Estimates of Martian crustal thickness from viscous relaxation of topography. J. Geophys. Res. 106, 5085-5098.

Norman, M.D., 1999. The composition and thickness of the crust of Mars estimated from rare earth elements and neodymium-isotopic compositions of Martian meteorites. Meteor. Planet. Sci. 34, 439-449.

Norman, M.D., 2002. Thickness and composition of the Martian crust revisited: implications of an ultradepleted mantle with $\mathrm{Nd}$ isotopic composition like that of QUE94201. In: Proc. Lunar Planet. Sci. Conf. 33th. Abstract 1175

Ojeda, G.Y., Whitman, D., 2002. Effect of windowing on lithosphere elastic thickness estimates obtained via the coherence method: results from northern South America. J. Geophys. Res. 107. doi:10.1029/2000JB000114 2275.

Ranalli, G., 1997. Rheology of the lithosphere in space and time. Geol. Soc. Spec. Publ. 121, 19-37.

Reese, C.C., Solomatov, V.S., Moresi, L.N., 1998. Heat transport efficiency for stagnant lid convection with dislocation viscosity: application to Mars and Venus. J. Geophys. Res. 103, 13643-13657.

Ruiz, J., 2007. The heat flow during the formation of ribbon terrains on Venus. Planet. Space Sci. 55, 2063-2070.

Ruiz, J., Tejero, R., 2000. Heat flows through the ice lithosphere of Europa. J. Geophys. Res. 105, 23,283-23,289.

Ruiz, J., McGovern, P.J., Tejero, R., 2006a. The early thermal and magnetic state of the cratered highlands of Mars. Earth Planet. Sci. Lett. 241, 2-10.

Ruiz, J., Tejero, R., McGovern, P.J., 2006b. Evidence for a differentiated crust at Solis Planum, Mars, from lithospheric strength and heat flow. Icarus 180, 308-313.

Ruiz, J., Gómez-Ortiz, D., Tejero, R., 2006c. Effective elastic thicknesses of the lithosphere in the Central Iberian Peninsula from heat flow: implications for the rheology of the continental lithospheric mantle. J. Geodyn. 41, 500-509.

Schultz, R.A., 2003. Seismotectonics of the Amenthes Rupes thrust fault population, Mars. Geophys. Res. Lett. 30. doi:10.1029/2002GL016475 1303.
Schultz, R.A., Lin, J., 2001. Three-dimensional normal faulting models of the Valles Marineris, Mars, and geodynamic implications. J. Geophys. Res. 106, 16549-16566.

Schultz, R.A., Watters, T.R., 2001. Forward mechanical modeling of the Amenthes Rupes thrust fault on Mars. Geophys. Res. Lett. 28, 4659-4662.

Shuster, D.L., Weiss, B.P., 2005. Martian surface paleotemperatures from thermochronology of meteorites. Science 309, 594-597.

Sibson, R.H., 1974. Frictional constraint on thrust, wrench and normal faults. Nature 249, 542-544.

Simons, F.J., van der Hilst, R.D., 2003. Seismic and mechanical anisotropy and the past and present deformation of the Australian lithosphere. Earth Planet. Sci. Lett. 211, 271-286.

Simons, F.J., Zuber, M.T., Korenaga, J., 2000. Isostatic response of the Australian lithosphere: estimation of effective elastic thickness and anisotropy using multitaper spectral analysis. J. Geophys. Res. 105, 19,163-19,184.

Slepian, D., 1978. Prolate spheroidal wave functions, Fourier analysis and uncertainty, V, the discrete case. Bell Syst. Tech. J. 57, 1371-1429.

Sohl, F., Spohn, T., 1997. The interior structure of Mars from SNC meteorites. J. Geophys. Res. 102, 1613-1635.

Solomon, S.C., Head, J.W., 1990. Heterogeneities in the thickness of the elastic lithosphere of Mars: constraints on heat flow and internal dynamics. J. Geophys. Res. 95, 11,073-11,083.

Swain, C.J., Kirby, J.F., 2003. The effect of 'noise' on estimates of the elastic thickness of the continental lithosphere by the coherence method. Geophys. Res. Lett. 30. doi:10.1029/2003GL017070 1574

Taylor, G.J., et al., 2003a. Igneous and aqueous processes on Mars: evidence from measurements of K and Th by the Mars Odyssey Gamma Ray Spectrometer. In: Proc. Sixth International Conference on Mars. Abstract 3207.

Taylor, G.J., et al., 2003b. Evolution of the Martian crust: evidence from preliminary potassium and thorium measurements Mars Odyssey GammaRay Spectrometer. In: Proc. Lunar Planet. Sci. Conf. 34th. Abstract 2004.

Taylor, G.J., et al., 2006. Bulk composition and early differentiation of Mars. J. Geophys. Res. 111. doi:10.1029/2005JE002645 E03S10 [Printed 112(E3), 2007].

Tesauro, M., Kaban, M.K., Cloeting, S.A.P.L., Hardebol, N.J., Beekman, F., 2007. 3D strength and gravity anomalies of the European lithosphere. Earth Planet. Sci. Lett. 263, 56-73.

Thomson, D.J., 1982. Spectrum estimation and harmonic analysis. Proc. IEEE 70, 1055-1096.

Toda, S., Stein, R.S., Richards-Dinger, K., Bozkurt, S., 2005. Forecasting the evolution of seismicity in southern California: animations built on earthquake stress transfer. J. Geophys. Res. 110. doi:10.1029/2004JB003415 B05S16.

Turcotte, D.L., Schubert, G., 2002. Geodynamics, second edition. Cambridge University Press, Cambridge.

Turcotte, D.L., Shcherbakov, R., Malamud, B.D., Kucinskas, A.B., 2002. Is the Martian crust also the Martian elastic lithosphere? J. Geophys. Res. 107. doi:10.1029/2001JE001594 5091.

Watters, T.R., 2003a. Lithospheric flexure and the origin of the dichotomy boundary on Mars. Geology 31, 271-274.

Watters, T.R., 2003b. Thrust faults along the dichotomy boundary in the eastern hemisphere of Mars. J. Geophys. Res. 108. doi:10.1029/2002JE001934 5054.

Watters, T.R., Robinson, M.S., 1999. Lobate scarps and the Martian crustal dichotomy. J. Geophys. Res. 104, 18981-18990.

Watters, T.R., McGovern, P.J., 2006. Lithospheric flexure and the evolution of the dichotomy boundary on Mars. Geophys. Res. Lett. 33, L08S05. doi:10.1029/ 2005 GL024325.

Watts, A.B., 2001. Isostasy and Flexure of the Lithosphere. Cambridge University Press, Cambridge.

Watts, A.B., Burov, E.B., 2003. Lithospheric strength and its relation to the elastic and seismogenetic layer thickness. Earth Planet. Sci. Lett. 213, 113-131.

Wieczorek, M.A., Zuber, M.T., 2004. Thickness of the Martian crust: improved constraints from geoid-to-topography ratios. J. Geophys. Res. 109, E01009. doi:10.1029/2003JE002153.

Zuber, M.T., et al., 2000. Internal structure and early thermal evolution of Mars from Mars Global Surveyor. Science 287, 1788-1793. 